\title{
A computationally simplistic poly-phasic approach to explore microbial communities from the Yucatan aquifer as a potential sources of novel natural products
}

\author{
Marfil-Santana Miguel David ${ }^{1}$, '’Connor-Sánchez Aileen $^{1}$, Ramírez-Prado Jorge Humberto ${ }^{1}$, \\ De los Santos-Briones Cesar ${ }^{1}$, López-Aguiar ${ }^{2}$, Lluvia Korynthia, Rojas-Herrera Rafael, \\ Lago-Lestón Asunción ${ }^{4}$, and Prieto-Davó Alejandra ${ }^{2 \star}$ \\ ${ }^{1}$ Center for Scientific Investigation of Yucatan (CICY), Calle 43 No. 130, Colonia Chuburná de Hidalgo, Mérida, Yucatán, C.P. 97200, Mexico \\ ${ }^{2}$ National Autonomous University of Mexico (UNAM), School of Chemistry, Campus Sisal, \\ Puerto de Abrigo s/n Municipio de Hunucmá, Sisal, Yucatan, C.P. 97356, Mexico \\ ${ }^{3}$ School of Chemical Engeneering, Autonomous University of Yucatan (UADY), Periférico Norte Kilometro 33.5, \\ Chuburná de Hidalgo Inn, Mérida, Yucatán, C.P. 97203, Mexico \\ ${ }^{4}$ Post Graduate Studies and Research Center of Ensenada (CICESE), Ensenada, Baja California, C.P. 22860, Mexico
}

In the article by David et al. published in Journal of Microbiology 2016; $54,774-781$, the names of all authors should be modified as below.

\footnotetext{
Miguel David Marfil-Santana ${ }^{1}$, Aileen O’Connor-Sánchez ${ }^{1}$, Jorge Humberto Ramírez-Prado ${ }^{1}$, Cesar De los Santos-Briones ${ }^{1}$, Lluvia Korynthia López-Aguiar ${ }^{2}$, Rafael Rojas-Herrera ${ }^{3}$, Asunción Lago-Lestón ${ }^{4}$, and Alejandra Prieto-Davó ${ }^{2 \times}$
} 